\title{
Abstract of Doctoral Dissertation Food Security in South Asia: Implications for Public Policy"
}

Harpreet Kaur

Assistant Professor, Department of Economics, Sri Guru Gobind Singh College of Commerce, University of Delhi, New Delhi-110034, India; kaurharpreet@sggscc.ac.in

\section{Introduction}

The Sustainable Development Goals (SDGs), the successors of the Millennium Development Goals (MDGs) have ensured a renewed commitment to end hunger and global poverty by 2030 . Specifically, the second SDG, calls for measures "To end hunger, achieve food security and improved nutrition, and promote sustainable agriculture". Food security as a concept is complex and has evolved overtime moving away from a strong focus on food availability to a multifaceted approach that also takes into account food accessibility, food utilisation and food stability. The complexities of achieving food security have increased due to the convoluted interplay of changing demographics and consumption patterns, climate change, impact of economic growth and trade at the national and international level.

South Asia is home to more than one third of the undernourished population of the World. The prevalence of undernourishment continues to be high and the region has not been able to meet the MDGs of reducing the number and proportion of people who suffer from hunger by half by 2015. The performance of the South Asian region seems even more dismal when the economic growth achieved by the countries in the region is considered. The five South Asian economies of Bangladesh, India, Nepal, Pakistan and Sri Lanka grew at an average rate of 5.32 per cent per annum between 2000 and 2013, exceeding the 2.7 percent World average. These economies have also made rapid strides in food production with food production in Bangladesh, India, Nepal, Pakistan, and Sri Lanka having increased by $4.5,30,30.8,22.17$ and 22.71 percent respectively between 2004 and 2012. However, despite this rapid economic growth and increased food production the number of undernourished people in this region remains unacceptably high. These disadvantaged people live at the bottom of society, suffering daily extreme hardship. The region also has the highest rates of undernourishment in children and the largest number of undernourished children in the world.

The large number of food insecure population is highly susceptible to rising food prices which are capable of pushing people further down below the poverty line and increase their vulnerabilities. Falling agricultural production and productivity and limited land availability are critical concerns for food availability. Climate change and conflict are two issues that are significantly undermining food security in the region and need to be addressed urgently. High levels of child malnutrition have shifted the focus to diet quality and diet diversity in the region. The present study focuses on understanding these issues on a contextual basis for South Asia and offers policy solutions specific to the region.

\section{Objectives, Data Sets and Methodology}

Food prices have a close bearing on food security captured through the dimensions of food availability, accessibility, food utilisation and stability in terms of susceptibility to external factors. For the average household in South Asia, food takes close to half of total spending. This high percentage perceptibly makes South Asian populations very vulnerable to food price increases. The first objective of the study is to understand the determinants of food price inflation in the five countries of South Asia. An econometric analysis, incorporating panel data fixed effects regression and dynamic panel data estimation tech-

"This is an abstract of the doctoral thesis, submitted to the Faculty of Management Studies, University of Delhi, under the supervision of Prof. Simrit Kaur. 
niques involving one step difference Generalised Method of Moments (GMM) is undertaken to study the correlates of food price inflation in South Asia. GMM is employed as our model is dynamic, with the lagged value of the dependent variable of consumer food price index also being as an explanatory variable, giving rise to the high possibility of the explanatory variable being correlated with the error term. The impact of domestic demand (food access) and supply side factors on national food prices, along with the impact of external factors such as global food and fuel prices, exchange rates, food imports, road density, political stability, money supply and budgetary deficit of the government is examined for the period 1990-2014.

Global warming is a primary cause of climate change and is a critical issue for the region. Climate change has perilous impacts on agriculture, the primary source of livelihood of a significant proportion of the region's population, as well as on food security through increased volatility in food production, loss of infrastructure and through disease and mass displacement. The second objective of the study involves anlaysing the climate change trends (as captured by precipitation and temperature over the period 1901 to 2014) and its impact on the region's agricultural production and food security over the period 1989 to 2014 . An important methodological contribution is estimating the deviations in rainfall and temperature from their respective pre-structural break averages, using Bai-Perron tests, as well as from pre-industrialisation averages. Thereafter, the non-linear impact of deviations of climate variables is examined using panel data regressions.

Densely populated South Asia accounted for 84 per cent of violent terrorist attacks and 95 percent of related fatalities in the world. The region has also witnessed considerable increases in conflict. Massive disruptions to food systems caused by climate-related disasters and destruction and displacement of armed conflict take a severe toll on food security. The third objective of the study is concerned with empirically examining if armed conflicts have a significant impact on food security in the region, focusing on the differential impact of prolonged conflicts along with interactions of climate change and conflicts.

Dietary diversity captures the number of different kinds of food or food groups that people eat and is an important outcome in itself. Nutrient adequacy is an important component of food security and there is a pertinent need to move away from calories that are unable to account for the 'hidden hunger' created by micronutrient deficiencies.
With the continued problem of malnutrition plaguing the region, especially its largest country India, it is important to focus on dietary diversity and factors affecting it. The final objective of the study is to estimate the relationship between dietary diversity and its correlates at the household, district and state level for rural farm and non-farm Indian households using unit level data from the $68^{\text {th }}$ round of the NSS (Schedule Type 1) Household Consumer Expenditure data pertaining to the year 2011-12. Ordinary Least Squares (OLS) regression as well as Quantile Regression (QR) analysis is employed for the analysis.

\section{Results and Policy Implications}

According to our empirical results lagged domestic food prices, global food prices, and domestic factors including, economic access, distribution networks and political stability are important correlates of domestic food prices. Food production indices have country specific differential impacts on food prices. Exchange rates and extent of dependence of food imports, as well as budgetary deficits also significantly impact food prices in these South Asian economies while money supply appears to have a limited impact on food prices.

Regarding the second objective of studying the relation between climate change and food security, the empirical investigation using three-year moving averages indicates that climate variables, especially deviations in average maximum temperatures, adversely impact agricultural production and food security. The estimates also indicate that larger the deviation of maximum temperature from the trend, the higher is the adverse impact, indicating non-linearity in the relationships. Our results also indicate that the effect of precipitation deviation, where significant, is adverse for agricultural production. Interestingly, our findings indicate that a rise in deviation of average minimum temperature impacts agriculture and cereal production as well as food security favourably. This is reflective of climate change having a non-homogenous impact.

Our econometric findings based on panel fixed effects regression analysis indicate that both conflicts and climate change worsen the already precarious food security situation in South Asia. In fact, the impact is even greater when prolonged conflicts are considered. Analysing conflict-climate interactions, food insecurity appears to further worsen with temperatures deviating from their 
pre-structural break averages, when considered along with prolonged armed conflicts.

Considering diet quality, households with higher expenditures, smaller dependency ratios and household sizes, headed by females with education levels beyond the primary level and belonging to higher social classes are found to have higher dietary diversities irrespective of whether they are households from farm or non-farm sectors. Greater agricultural production diversity, higher proportion of households using bank facilities and price of pulses favourably impact diet diversity of all, farm and non-farm households. Cereal prices, increased rainfall deviations and rural road density significantly but negatively impact diet diversity. The impact of rural road density for farm and non-farm households considered separately is significant and favourable for lower quantiles of diet diversity.

The study suggests that it is important to strengthen effective safety nets; adopt measures that enhance agricultural production, diversification and productivity; improve physical infrastructure especially irrigation and roads; lay emphasis on climate change adaptation and mitigation policies; and address the root causes of armed conflict, to address aspects of food insecurity including diet diversification. Additionally, increased regional cooperation amongst South Asian economies in terms of technology sharing, water resources management and building regional food stocks would assist in addressing food insecurity concerns of the South Asian region. 